\title{
Virulência e formação de biofilme microbiano por Enterococcus faecalis isolados de swabs cloacais de frangos de corte infectados com Eimeria spp. ${ }^{1}$
}

\author{
Ana Paula V. Cassenego ${ }^{2}$, Juliana Ellwanger², Pedro A. d'Azevedo ${ }^{3}$, Andreia M.L. \\ Ribeiro $^{4}$, Jeverson Frazzon ${ }^{5}$ e Ana Paula G. Frazzon ${ }^{2}$
}

\begin{abstract}
Cassenego A.P.V., Ellwanger J., d'Azevedo P.A., Ribeiro A.M.L., Frazzon J. \& Frazzon A.P.G. 2013. [Virulence and biofilm formation by Enterococcus faecalis isolates from cloacal swabs of broilers infected with Eimeria spp.] Virulência e formação de biofilme microbiano por Enterococcus faecalis isolados de swabs cloacais de frangos de corte infectados com Eimeria spp. Pesquisa Veterinária Brasileira 33(12):1433-1440. Departamento de Microbiologia, Instituto de Ciências Básicas da Saúde, Universidade Federal do Rio Grande do Sul, Rua Sarmento Leite 500, Porto Alegre, RS 90050-170, Brazil. E-mail: ana.cassenego@ufrgs.br

The microbiota dynamics in the gastrointestinal tract (GT) of animals can be disrupted by pathogens, such as Eimeria spp. Enterococci are saprophytic bacteria that colonize the GT of mammals and birds. The influence on the intestinal microbiota is related to the adaptive capacity of bacteria to adhere to host cells and colonize the mucosal cells. The aim of this study was to analyze the frequency of virulence genes ace, agg and bopABCD operon in Enterococcus faecalis isolated from cloacal swabs of broilers challenged with Eimeria spp. and fed with a standard diet supplemented or not with anticoccidial (monensin), and, also to evaluate for the ability of these strains to form biofilms under in vitro conditions. A total of 70 E. faecalis were selected and the agg gene was more frequent in strains isolated from the broilers treated with anticoccidial $(92.3 \%)$ when compared to the group that not received anticoccidial (70.5\%). On the other hand, the ace and bopABCD operon genes showed no significant difference between the two groups of broilers $(P>0.005)$. The E. faecalis isolated from the broilers treated with anticoccidial showed a higher frequency of strong biofilm formation when growing in medium supplemented with glucose (92.3$88.5 \%)$ and urine $(77 \%)$ when compared with enterococci isolated from broilers that not received anticoccidial. It was observed that $E$. faecalis isolated from broilers treated with anticoccidial showed a higher frequency of virulence factors genes and stronger biofilms formation, indicating better adaptation of the isolates in healthy intestinal environment.
\end{abstract}

INDEX TERMS: Enterococcus faecalis, biofilm, virulence factors, broilers, Eimeria spp., anticoccidial.

\footnotetext{
${ }^{1}$ Recebido em 12 de julho de 2013.

Aceito para publicação em 28 de outubro de 2013.

${ }^{2}$ Departamento de Microbiologia, Instituto de Ciências Básicas de Saúde, Universidade Federal do Rio Grande do Sul (UFRGS), Rua Sarmento Leite 500, Porto Alegre, RS 90050-170, Brasil. *Autor para correspondência: ana.cassenego@ufrgs.br

${ }^{3}$ Departamento de Microbiologia e Parasitologia, Universidade Federal de Ciências de Saúde de Porto Alegre (UFCSPA), Rua Sarmento Leite 245, Porto Alegre, RS 90050-170.

${ }^{4}$ Departamento de Zootecnia, UFRGS, Av. Bento Gonçalves 7712, Porto Alegre, RS 91540-000.

${ }^{5}$ Instituto de Ciência e Tecnologia dos Alimentos, UFRGS, Av. Bento Gonçalves 9500, Porto Alegre, RS 91501-970.
}

RESUMO.- A dinâmica da microbiota no trato gastrointestinal (TG) de animais pode ser afetada por patógenos, tais como Eimeria spp. Os enterococos são bactérias saprófitas que colonizam o TG de mamíferos e aves. A influência sobre a microbiota intestinal está relacionada com a capacidade de adaptação das bactérias em se aderir às células hospedeiras e de colonizar as células das mucosas. 0 objetivo deste estudo foi analisar a frequência de genes de virulência ace, agg e operon do bopABCD em Enterococcus faecalis isolados de swabs cloacais de frangos de corte desafiados com Eimeria spp e alimentados com dietas padrões suplementadas ou não com anticoccidiano (mo- 
nesina) e também avaliar a capacidade dessas cepas em formar biofilmes sob condições in vitro. Um total de $70 \mathrm{E}$. faecalis foram selecionadas e o gene agg foi mais freqüente em cepas isoladas de frangos de corte alimentados com anticoccidiano (92,3\%) quando comparado ao grupo que não recebeu anticoccidiano (70,5\%). Por outro lado, os genes ace e do operon bopABCD não demostraram nenhuma diferença significativa entre os dois grupos de frangos $(\mathrm{P}>0,005)$. Os E. faecalis isolados de frangos de corte alimentados com anticoccidiano demostraram uma maior frequência de fortes aderentes quando crescendo em meio suplementado com glicose $(92,3-88,5 \%)$ e urina $(77 \%)$, quando comparado com enterococos isolados de frangos que não receberam anticoccidiano. Observou-se que $E$. faecalis isolados de frangos tratados com anticoccidiano mostraram uma maior frequêencia dos genes dos fatores de virulência e de perfil de fortes formadores de biofilme, o que indica uma melhor adaptação dos isolados em ambiente intestinal saudável.

TERMOS DE INDEXAÇÃO: Enterococcus faecalis, biofilme, fatores de virulência, frangos de corte, Eimeria spp., anticoccidiano.

\section{INTRODUÇ̃̃o}

Enterococos são bactérias saprofíticas que colonizam o trato gastrointestinal de mamíferos e pássaros (Murray 1990, Martynova-Van Klein et al. 2012). A colonização de animais pelas diferentes espécies de enterococos está sujeita a variações que podem ser associadas a fatores como a localização geográfica, dieta, idade, espécie de animal e também variações sazonais. Na produção de animais como aves, bovinos e suínos, as espécies mais comumente isoladas são Enterococcus faecalis, Enterococcus faecium, Enterococcus hirae, Enterococcus cecorum e Enterococcus durans. Em estudo realizado na região Sul do Brasil, foi observado que a espécie E. faecalis foi a mais frequente $(40 \%)$ em amostras de cloacas de frangos de corte, seguida de E. casseliflavus/E. gallinarum $(10,8 \%)$, E. mundtii $(10,8 \%)$, E. faecium $(10,8 \%)$, E. columbae (5,8\%) e E. gallinarum (4,2\%) (Cassenego et al. 2011).

A virulência de enterococos pode ser aumentada pela expressão de fatores de virulência como a proteína de superfície de adesão da matriz à molécula (Ace), produzida sob condições fisiológicas, mas que contribui para a patogênese da infecção (Shepard \& Gilmore 2002), assim como a proteína de agregação (Agg) que facilita a agregação entre as bactérias e parece estar envolvida na virulência em E. faecalis (Duprè et al. 2003). 0 operon bopABCD contém genes responsáveis pela prolongação da bacteremia por cepas de E. faecalis produtoras de biofilme e seu envolvimento na utilização da maltose sugere uma nova via catabólica no metabolismo de bactérias ácido láticas semelhante ao lócus MalPBMR em Lactococcus lactis (Hufnagel et al. 2004, LeBreton et al. 2005). 0 gene bopA codifica uma glicosil-transferase, o gene bopB por sua vez, codifica uma $\beta$-fosfoglicomutase, o gene bopC uma aldose-1-epimerase e o bopD uma proteína reguladora que tem capacidade de restaurar parcialmente a formação do biofilme, sendo importante no transporte de carboidrato aos tecidos e pode ser controlado positiva ou negativamente por bopABC (LeBreton et al. 2005, Bourgogne et al. 2006, Creti et al. 2006, Vebo et al. 2009).

A habilidade em formar biofilme é uma importante característica de virulência das bactérias (Donelli \& Guaglianone 2004). O biofilme é um complexo multicelular caracterizado por colônias aderentes circundadas por uma matriz exopolissacarídica que protege as bactérias contra agentes antimicrobianos e fagócitos, permitindo sua sobrevivência em ambientes hostis (George et al. 2005, Chai et al. 2007). Deste modo, a detecção de cepas produtoras de biofilme é de grande importância para o estabelecimento de políticas de controle, uma vez que falhas no processo de higienização permitem que resíduos aderidos aos equipamentos e superfícies transformem-se em potencial fonte de contaminação na indústria de alimentos.

A microbiota intestinal tem efeito significativo na nutrição, saúde e desenvolvimento do sistema digestivo do hospedeiro (Barrow 1992). Esta interação é muito complexa e depende da composição e atividade de sua microbiota que pode exercer efeito positivo ou negativo na saúde e crescimento de aves, por exemplo, quando patógenos atacam a mucosa intestinal comprometendo a integridade, o funcionamento tecidual e seu sistema imune (Droleskey et al. 1994, Neish 2002). Dentre os parasitas que afetam o intestino das aves se destacam os protozoários e helmintos, sendo os protozoários de Eimeria spp., agentes etológicos de coccidiose aviária, considerada a doença mais importante na indústria avícola (Smith \& Beal 2008).

Os sinais clínicos mais graves de infecção por Eimeria spp. incluem diarréia, diminuição do ganho de peso, baixa conversão alimentar, podendo haver hemorragia intestinal e mortalidade. Ocorre a destruição de vilosidades, diminuição do pH intestinal, diminuição da viscosidade intestinal e predisposição a infecções secundárias. A gravidade da doença depende da espécie do parasita, podendo haver variação de patogenicidade e também está sujeita a fatores do hospedeiro como linhagem e idade. A importância em se elucidar a dinâmica da microbiota no trato gastrintestinal dos animais é reconhecida e sabe-se que fatores como idade dos animais, dieta, tipo de criação e presença de patógenos, tais como, os coccídios Eimeria spp. podem influenciar a microbiota do intestino. Esta influência sobre a microbiota intestinal esta relacionada com a capacidade adaptativa das bactérias em se aderir às células e colonizar as mucosas (Williams 2005, Santos et al. 2008).

0 objetivo deste estudo foi analisar a frequência dos genes agg, ace e do operon bopABCD envolvidos com a virulência e formação de biofilme em Enterococcus faecalis isolados de swabs cloacais de frangos de corte desafiados com Eimeria spp. e alimentados com dietas suplementadas ou não com anticoccidiano e avaliação da capacidade dessas cepas em formar biofilmes a $36^{\circ} \mathrm{C} \mathrm{e} 42^{\circ} \mathrm{C}$, crescendo em caldo Luria-Bertani suplementado com $10 \%$ de sangue, ou $10 \%$ de urina ou $0,75 \%$ de glicose.

\section{MATERIAL E MÉTODOS}

Foram selecionados 70 Enterococcus faecalis isolados de um estudo anterior realizado pelo grupo, onde avaliou-se a diversidade de 
enterococos isolados de swabs cloacais de frangos machos Cobb 500 com 28 dias alimentados com uma dieta baseada em milho e farelo de soja, óleos vegetais, minerais e vitaminas e suplementados $(n=44)$ ou não $(n=26)$ com 100 ppm de anticoccidiano (monensina). Aos 14 dias de idade, todas as aves receberam uma solução contendo $5 \times 10^{4}$ e $1 \times 10^{4}$ oocistos/animal de Eimeria maxima e Eimeria acervulina, respectivamente (Cassenego et al. 2011).

A confirmação da espécie Enterococcus faecalis de todos os isolados selecionados foi realizada pela técnica de reação em cadeia (PCR) utilizando os oligonucleotídeos iniciadores espécie-específico $d d l_{E \text {-faecalis }}($ Quadro 1). A reação da PCR foi realizada no termociclador (Amplitherm- Thermal Cyclers-) sob as seguintes condições: desnaturação inicial a $94^{\circ} \mathrm{C}$ por 5 minutos, seguida de 40 ciclos de $94^{\circ} \mathrm{C}$ por 1 minuto; temperatura de anelamento $52^{\circ} \mathrm{C}$ por 1 minuto e extensão a $72^{\circ} \mathrm{C}$ por 1 minuto, com extensão final a $72^{\circ} \mathrm{C}$ por 10 minutos. Os produtos da amplificação da PCR foram visualizados em gel de agarose 1,5\%, corado com brometo de etídio e observado através de luz ultravioleta (UV).

Ensaios in vitro para a detecção de atividade da enzima gelatinase em ágar suplementado com gelatina (4\%) foram realizados a $36^{\circ} \mathrm{C}$ (temperatura corporal de mamíferos) e $42^{\circ} \mathrm{C}$ (temperatura corporal de aves), seguindo o protocolo descrito por Eaton \& Gasson (2001).

O DNA total de todos os isolados foi extraído pelo método de Fredricks \& Relman (1997) com modificações. Uma alíquota de $5 \mu \mathrm{L}$ do inóculo incubado por 16 horas em caldo Infusão de Cérebro e Coração (BHI) à $37^{\circ} \mathrm{C}$ foi centrifugada por 5 minutos a 300rpm. 0 sobrenadante foi descartado e o pellet foi lavado três vezes com $1 \mathrm{~mL}$ de tampão TE $1 \mathrm{x}$ e suspendido em $100 \mu \mathrm{L}$ do mesmo tampão. Ao pellet foi adicionado $100 \mu \mathrm{L}$ de TE ${ }^{5} \mathrm{~N}, 10$ $\%$ do volume de SDS e $5 \mu \mathrm{L}$ de Proteinase $\mathrm{K}(20 \mathrm{mg} / \mathrm{ml})$. A seguir, incubou-se em banho-maria por 1 hora a $55^{\circ} \mathrm{C}$. Adicionaram-se $15 \mu \mathrm{l} \mathrm{NaCl} 5 \mathrm{M}$ e $200 \mu \mathrm{l}$ de fenol em fração $1: 1$, seguido de agitação em vórtex. As amostras foram colocadas em rotor por 30 minutos e após, centrifugadas por 30 minutos a $14000 \mathrm{rpm}$. A fase aquosa foi coletada e transferida para outro microtubo, adicionando 1 $\mathrm{mL}$ de etanol absoluto. As amostras foram incubadas por 1 hora a $-20^{\circ} \mathrm{C}$ e centrifugadas por 15 minutos a $13.000 \mathrm{rpm}$ e, logo após, desprezou-se o sobrenadante e o pellet foi suspendido em $100 \mu \mathrm{L}$ de TE e $5 \mu \mathrm{L}$ de RNase. As amostras foram incubadas por $30 \mathrm{mi}$ nutos a $37^{\circ} \mathrm{C}$ e $6 \mu \mathrm{L}$ do produto foram aplicados em gel de agarose $1 \%$ para analisar a concentração e a qualidade do material.

A detecção da presença dos genes agg, ace e do operon bo$p A B C D$ envolvidos com a virulência e formação de biofilme, foi realizada por PCR. A reação foi realizada em termociclador (Amplitherm- Thermal Cyclers). As sequências dos oligonucleotídeos iniciadores e as temperaturas de anelamento estão demonstradas no Quadro 1. Para a reação de PCR foram utilizados: $1 \mu \mathrm{L}$ de DNA bacteriano, $10 \mu \mathrm{M}$ de cada oligonucleotídeo iniciador, $200 \mu \mathrm{M}$ de cada dNTP, $1 \mathrm{U}$ de Taq DNA Polimerase, 1,5mM de $\mathrm{MgCl}_{2}$, tampão de reação e água MilliQ. Os fragmentos foram amplificados em termociclador sob as seguintes condições: desnaturação inicial a $94^{\circ} \mathrm{C}$ por 5 minutos, seguida de 40 ciclos de $94^{\circ} \mathrm{C}$ por 1 minuto; temperatura de anelamento (Quadro 1) por 1 minuto e extensão a $72^{\circ} \mathrm{C}$ por 1 minuto, com extensão final a $72^{\circ} \mathrm{C}$ por 10 minutos. Os produtos da amplificação da PCR foram visualizados em gel de agarose $1,5 \%$, corado com brometo de etídio e observado através de luz ultravioleta (UV).

Os ensaios de biofilme foram realizados em todos os isolados de acordo com protocolo modificado de Stepanovic et al. (2000). As amostras foram incubadas por $16 \mathrm{~h}$ a $37^{\circ} \mathrm{C}$ em ágar BHI. As culturas foram diluídas em $5 \mathrm{~mL}$ de solução salina $(0,9 \%)$ até atingir a concentração de $1,5 \times 10^{8}$ células bacterianas $/ \mathrm{mL}$ de solução. Após, foram depositadas em microplacas de poliestireno com 96 poços utilizando caldo Luria Bertani (LB) acrescido de $10 \%$ de sangue (LBS) ou LB acrescido de $10 \%$ de urina (LBU) ou LB acrescido de $0,75 \%$ de glicose (LBG). Os isolados foram crescidos a $37^{\circ} \mathrm{C}$ por 16 horas com todos os suplementos citados e os ensaios realizados com meio acrescido de glicose $(0,75 \%)$ ou sangue $(10 \%)$ também foram incubados a $42^{\circ} \mathrm{C}$. Após, as células planctônicas foram coletadas por aspiração e os poços lavados três vezes com $200 \mu \mathrm{L}$ de solução salina. Para fixação das células aderidas, foram adicionados $150 \mu \mathrm{L}$ de álcool metílico em cada poço por 15 minutos. Após, as placas foram submetidas à secagem em temperatura ambiente por 16 horas. Para determinar a quantificação do biofilme formado, $150 \mu \mathrm{L}$ de uma solução de cristal violeta $0,5 \%$ foram adicionados em cada poço e as placas incubadas por $15 \mathrm{mi}-$ nutos e lavadas em água corrente. Para leitura, $150 \mu \mathrm{L}$ de álcool 95\% foram adicionados a cada poço. A densidade ótica (D0) dos biofilmes bacterianos foi determinada em leitor espectrofotométrico de microplacas utilizando filtro de comprimento de onda de $595 \mathrm{~nm}$. Cada teste foi realizado em oitoplicatas e a formação do biofilme determinada a partir da densidade ótica obtida seguindo os critérios de Stepanovic et al. (2000). A cepa Staphylococcus epidermidis (ATCC 35984) foi utilizada como controle positivo (forte aderente) em todos os ensaios.

A DO média do controle negativo (DOc) foi utilizada como ponto de corte. Os isolados foram classificados como: DO $\leq \mathrm{DOc}$

\begin{tabular}{|c|c|c|c|c|}
\hline Genes & $\begin{array}{l}\text { Oligonucleotídeos } \\
\text { iniciadores }\left(5^{\prime}-3^{\prime}\right)\end{array}$ & Amplicon (pb)* & $\begin{array}{l}\text { Temperatura de } \\
\text { anelamento }\end{array}$ & Referência \\
\hline ddlE-faecalis & $\begin{array}{l}\text { CACCTGAAGAAACAGGC } \\
\text { ATGGCTACTTCAATTTCACG }\end{array}$ & 475 & $520 \mathrm{C}$ & Depardieu et al. (2004) \\
\hline agg & $\begin{array}{l}\text { AAGAAAAAGTAGACCAAC } \\
\text { AACGGCAAGACAAGTAAATA }\end{array}$ & 1553 & $560 \mathrm{C}$ & Eaton \& Gasson (2001) \\
\hline ace & $\begin{array}{c}\text { AAAGTAGAATTAGATCACAC } \\
\text { TCTATCACATTCGGTTGCG }\end{array}$ & 320 & $560 \mathrm{C}$ & Duprè et al. (2003) \\
\hline bopA & $\begin{array}{l}\text { CAGCGACATGGACAGCCTAC } \\
\text { TTGCAGGACCGTCGAGTAAA }\end{array}$ & 108 & $480 \mathrm{C}$ & Neste estudo \\
\hline bopB & $\begin{array}{l}\text { ATGACAGAATCCAAAACTGC } \\
\text { TTACGAAGGGGTTGATTCAC }\end{array}$ & 687 & $480 \mathrm{C}$ & Neste estudo \\
\hline bopC & $\begin{array}{l}\text { TTATAGAAGGTTAAATTGAT } \\
\text { ATGAAGGATAATCGTATCAC }\end{array}$ & 1010 & $480 \mathrm{C}$ & Neste estudo \\
\hline bopD & GGCTTCCTCGTTGATGGCTTC & 126 & $600 \mathrm{C}$ & Hufnagel et al. (2004) \\
\hline
\end{tabular}

\footnotetext{
$* \mathrm{pb}=$ pares de bases.
} 
Não-aderente; DOc $<$ DO $\leq$ 2x DOc Fraco aderente; 2x DOc $<$ DO $\leq$ 4x DOc Moderado aderente; 4x DOc $<$ DO Forte aderente.

Os resultados obtidos em score seguiram a normalidade e foram submetidos à análise da variância (ANOVA) e ao teste de Kruskal-Wallis a $1 \%$ (sendo $P \leq 0,05$ ), para comparar a presença dos fatores de virulência e a intensidade de formação de biofilme entre os isolados, os suplementos e as temperaturas utilizadas. Para tanto, utilizou-se o programa estatístico Graphpad Prism versão 5.0.

\section{RESULTADOS}

Todos os isolados selecionados confirmaram pertencer à espécie Enterococcus faecalis através de pesquisa do gene $d d l_{E-f a c a l i s}$ e demonstraram maior atividade da enzima gelatinase em temperatura de $36^{\circ} \mathrm{C}$ em detrimento a $42^{\circ} \mathrm{C}$. No que se refere à dieta empregada aos animais, todos os isolados $(100 \%)$ apresentaram atividade gelatinolítica quando submetidos a $36^{\circ} \mathrm{C}$ de crescimento independente da presença do ionóforo. Por outro lado, sob crescimento a $42^{\circ} \mathrm{C}$, temperatura corpórea das aves, o nível de atividade da enzima foi variável entre $81,8 \%$ na ausência de anticoccidiano e $88,5 \%$ na presença destes, não apresentando grande diferença no comportamento fenotípico referente à dieta empregada.

A distribuição dos genes ace, agg e do operon bop $A B C D$ avaliada de acordo com a presença ou não de anticoccidiano na dieta dos frangos está demonstrada no Quadro 2. 0 gene agg apresentou maior frequência nos E. faecalis isolados dos frangos que receberam a dieta suplementada com anticoccidiano e não apresentou quadro clínico diarréico $(92,3 \%)$, quando comparado ao grupo que não recebeu cocidiostáticos (70,5\%). 0 gene ace não apresentou variação significativa na sua frequência entre os dois grupos de

Quadro 2. Frequência dos genes codificadores dos fatores de virulência detectados em cepas de Enterococcus faecalis isolados de frangos de corte infectados com Eimeria spp.*

\begin{tabular}{ccccccc}
\hline Genes & \multicolumn{2}{c}{$\begin{array}{c}\text { Dieta sem } \\
\text { anticoccidiano (n=44) }\end{array}$} & \multicolumn{2}{c}{$\begin{array}{c}\text { Dieta com } \\
\text { anticoccidiano (n=26) }\end{array}$} & Total (n=70) \\
\hline & $\mathrm{n}$ & $\%$ & $\mathrm{n}$ & $\%$ & $\mathrm{n}$ & $\%$ \\
agg & 31 & 70,5 & 24 & 92,3 & 56 & 80 \\
ace & 40 & 90,9 & 25 & 96,1 & 65 & 92,85 \\
bopA & 43 & 97,7 & 26 & 100 & 69 & 98,6 \\
bopB & 37 & 84,1 & 23 & 88,4 & 60 & 85,7 \\
bopC & 44 & 100 & 25 & 96,1 & 69 & 98,6 \\
bopD & 44 & 100 & 26 & 100 & 70 & 100 \\
* P $<0$ 05 & & & & & &
\end{tabular}

frangos $(90,9-96,1 \%)$. Os genes do operon bopABCD foram identificados em ambos os grupos dos animais e sua frequência não foi significativamente afetada pela presença ou ausência de anticoccidiano na dieta dos frangos $(P>0,05)$. Todos os isolados apresentaram mais de um gene pesquisados.

A capacidade de formar biofilme foi observada em todos os isolados quando cultivados no meio LB suplementado com $10 \%$ de sangue, $10 \%$ de urina ou $0,75 \%$ de glicose nas temperaturas de $36^{\circ} \mathrm{C}$ e $42^{\circ} \mathrm{C}$. Os perfis fenotípicos de formação de biofilme dos isolados de E. faecalis de acordo com a dieta empregada, substratos dos meios de cultura e temperaturas de crescimento utilizadas estão demonstrados no Quadro 3. Isolados de E. faecalis provenientes dos frangos de corte submetidos à dieta com anticoccidiano apresentaram maiores índices de forte aderente quando cultivados na presença de $0.75 \%$ de glicose $(92,3-88,5 \%)$ e $10 \%$ de urina $(77 \%)$ quando comparados com enterococos isolados de frangos que não receberam anticoccidiano na dieta. Por outro lado, quando os mesmos isolados foram cultivados na presença de $10 \%$ de sangue, observou-se uma elevada frequência de isolados moderados formadores de biofilme em ambas as temperaturas e dietas (52-69\%).

\section{DISCUSSÃO}

Neste estudo foi possível constatar-se um mecanismo de resposta adaptativa quanto à atividade da enzima gelatinase dos Enterococcus faecalis isolados de swabs cloacais de frangos de corte em função da temperatura de crescimento empregada. No entanto, apesar da temperatura corpórea das aves, nem todos os isolados de frangos mostraram tal capacidade de adaptação, visto que o índice de atividade da enzima diminuiu com o aumento da temperatura. Marinho (2010) obteve resultados similares no fenótipo de gelatinase em diferentes temperaturas de crescimento $(28,37$ e $45^{\circ} \mathrm{C}$ ) em $E$. faecalis isolados de alimentos e amostras clínicas. Yeong et al. (2011) também observaram diferenças na atividade da enzima gelatinase em E. faecalis isolados de frangos de diferentes sistemas de criação, onde 90,9\% dos enterococos isolados de frangos de corte foram positivos para atividade da enzima gelatinase, quando comparados com $88 \%$ dos isolados provenientes de aves criadas em sistema extensivo. Por outro lado, os resultados observados para a atividade da enzima gelatinase são diferentes dos apresentados por Poeta et al. (2006) que pesquisaram a atividade de gelatinase em enterococos isolados de fezes

Quadro 3. Relação do fenótipo de formação de biofilme com os diferentes meios de cultura e temperaturas de incubação de $36^{\circ} \mathrm{C} \mathrm{e} 42^{\circ} \mathrm{C}$ em Enterococcus faecalis Intensidade de isolados produtores de biofilme (\%)

\begin{tabular}{|c|c|c|c|c|c|c|c|c|c|c|c|c|c|c|c|}
\hline \multirow[t]{3}{*}{ Dieta $^{\mathrm{d}}$} & \multicolumn{6}{|c|}{$\mathrm{LBG}^{\mathrm{a}}$} & \multicolumn{6}{|c|}{ LBS $^{b}$} & \multirow{2}{*}{\multicolumn{3}{|c|}{$\begin{array}{l}\mathrm{LBU}^{\mathrm{c}} \\
36^{\circ} \mathrm{C}\end{array}$}} \\
\hline & \multicolumn{3}{|c|}{$36^{\circ} \mathrm{C}$} & \multicolumn{3}{|c|}{$42^{\circ} \mathrm{C}$} & \multicolumn{3}{|c|}{$36^{\circ} \mathrm{C}$} & \multicolumn{3}{|c|}{$42^{\circ} \mathrm{C}$} & & & \\
\hline & $\mathrm{Fo}^{\mathrm{e}}$ & $\mathrm{M}^{\mathrm{e}}$ & $\mathrm{Fr}^{\mathrm{e}}$ & $\mathrm{Fo}^{\mathrm{e}}$ & $\mathrm{M}^{\mathrm{e}}$ & $\mathrm{Fr}^{\mathrm{e}}$ & $\mathrm{Fo}^{\mathrm{e}}$ & $\mathrm{M}^{\mathrm{e}}$ & $\mathrm{Fr}^{\mathrm{e}}$ & $\mathrm{Fo}^{\mathrm{e}}$ & $\mathrm{M}^{\mathrm{e}}$ & $\mathrm{Fr}^{\mathrm{e}}$ & $\mathrm{Fo}^{\mathrm{e}}$ & $\mathrm{M}^{\mathrm{e}}$ & $\mathrm{Fr}^{\mathrm{e}}$ \\
\hline S/Aco & 90,9 & 0 & 9,1 & 59,1 & 36,36 & 4,5 & 31,8 & 52,27 & 15,9 & 11,36 & 61,36 & 27,27 & 63,63 & 29,5 & 6,8 \\
\hline C/Aco & 92,3 & 7,7 & 7,7 & 88,5 & 88,5 & 0 & 23,1 & 69,2 & 7,7 & 23,1 & 53,85 & 23,1 & 77 & 19,2 & 3,85 \\
\hline
\end{tabular}

$\overline{{ }^{a} \mathrm{LBG}}=$ meio $\mathrm{LB}$ suplementado com $0,75 \%$ de glicose; ${ }^{\mathrm{b}} \mathrm{LBS}=$ meio LB suplementado com $10 \%$ de sangue; ${ }^{\mathrm{c}} \mathrm{LBU}=\mathrm{meio}$

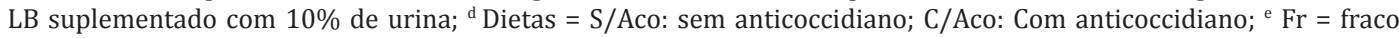
aderente; $\mathrm{M}=$ moderado aderente; Fo = forte aderente. 
de frangos de corte e observaram que apenas $47 \%$ destes apresentavam fenótipo positivo.

A atividade da enzima gelatinase é influenciada por diversos parâmetros ambientais, tais como meio de cultura, variação de $\mathrm{pH}$, diferença de atividade in vitro/in vivo, formação de cátions divalentes e diferentes fontes de carbono, anteriormente relatadas no que se refere à influência na atividade gelatinolítica das células bacterianas. A produção de gelatinase é sensível ao calor, principalmente quando em temperaturas maiores que $50^{\circ} \mathrm{C}$, sendo associada também com o tempo de crescimento. Sua atividade varia amplamente quando células bacterianas são suplementadas com diferentes carboidratos como fonte de carbono e aumentam na presença de arabinose, xilose, glicose, maltose e manose, enquanto diminuem com outros diversos açúcares (Pires-Bouças et al. 2010). Macovei et al. (2009) relataram a plasticidade genômica e a importância da pressão seletiva na manutenção da virulência bacteriana, onde alguns isolados, após longo período de descanso metabólico em temperaturas baixas $\left(4-8^{\circ} \mathrm{C}\right)$ e em subculturas, perderam sua capacidade de expressar a gelatinase.

A frequência do gene agg observado no presente estudo está de acordo com outros estudos com E. faecalis de isolados de amostras clínicas e alimentares (Eaton \& Gasson 2001, Franz et al. 2001, Mannu et al. 2003, Martín et al. 2006, Barbosa et al. 2010). 0 gene agg apresentou maior frequência nos E. faecalis isolados dos frangos, que receberam dieta suplementada de anticoccidiano $(92,3 \%)$ quando comparado ao grupo que não recebeu anticoccidiano (70,5\%). A diferença entre os índices apresentados pode estar relacionada ao quadro diarreico causado pela Eimeria spp., que causa uma modificação estrutural das vilosidades intestinais, levando a um encurtamento destas, resultando em diminuição da capacidade de absorção e predispõe os frangos a disbacteriose (Williams 2005). A função da proteína Agg tem sido relatada na bibliografia, como sendo responsável pelo aumento da aderência de Enterococcus ao epitélio intestinal e renal. Esta destruição das células epiteliais do intestino pode ter sido uma das causas da redução na frequência do gene agg nos E. faecalis isolados do grupo de frangos que não recebeu anticoccidiano. Em E. faecalis o gene agg está localizado em um plasmídeo responsivo a feromônios, causando agregação entre células doadoras e receptoras, facilitando a transferência de plasmídeos que podem carrear genes de virulência e resistência antimicrobiana (Barbosa et al. 2010). Portanto, um epitélio intestinal com possíveis danos teciduais e maior absorção de líquidos pelo interstício e luz intestinal, torna-se um ambiente desfavorável para agregação celular e posterior processo de estabelecimento de biofilme microbiano neste ambiente de crescimento. Apesar da diferença no percentual dos dois grupos tratados, os frangos que não receberam anticoccidiano na dieta também apresentaram alto percentual de genes dos fatores de virulência. Esses resultados concordam com os apresentados por Hume et al. (2012) que demonstram efeitos negativos da infecção por Eimeria, modificando a população microbiana do ceco. Tal fato foi anteriormente relatado, demonstrando que esse gênero de coccídios pode desenvolver um papel importante na pa- tologia de coccidioses cecais, tendo forte efeito na taxa da comunidade bacteriana dominante (Bradley \& Radhakrishnan 1973).

Por outro lado, o único trabalho que relata a influência do quadro clínico diarréico sobre os fatores de virulência, foi realizado em Escherichia coli isoladas de bezerros com e sem diarreia, observou que os fatores de virulência eram mais prevalentes em E. coli isoladas dos bezerros que apresentavam quadro clínico de diarreia, causado por vários agentes enteropatogênicos, entre eles, Eimeria spp. (Herrera-Luna et al. 2009). Em trabalho realizado por Martynova-Van Kley et al. (2012), uma análise de pirosequenciamento da microbiota bacteriana de frangos infectados com Eimeria spp. e tratados com óleos essenciais sugere que os animais tratados apresentaram uma modulação positiva na microbiota a qual pode causar impactos favoráveis ao hospedeiro.

0 gene ace que codifica uma proteína com características de adesina bacteriana e ligante a colágeno do tipo I, não apresentou variação significativa quanto à diferença nas frequências entre os dois grandes grupos de frangos $(P>0,05)$. Este gene tem sido apontado como um importante fator de virulência, onde sua deleção resulta em significativa atenuação de E. faecalis (Singh et al. 1998, Piekarska \& Jagielski 2007). Tal característica justifica a elevada frequência do gene em ambos os grupos de frangos. A frequência do gene ace em ambos os grupos está de acordo com outros estudos que avaliaram a presença deste gene em amostras de swabs cloacais de frangos. Diarra et al. (2010) detectaram o gene ace em todos os E. faecalis isolados de frangos pesquisados. Olsen et al. (2011) pesquisaram o gene ace em isolados clínicos e de frangos e detectaram a presença do gene em todas as amostras pesquisadas.

Os genes do operon bopABCD foram identificados em ambos os grupos de frangos e sua frequência não foi significativamente afetada pela presença ou ausência de anticoccidiano na ração. 0 operon bop tem sido descrito no envolvimento do metabolismo da maltose e formação de biofilme. Os genes bopA, bopC e bopD foram detectados com elevada frequência em ambos os grupos de frangos. 0 gene bop $B$ também não apresentou diferenças entre os frangos que receberam ou não anticoccidiano na ração, entretanto apresentou uma frequência menor quando comparado com bopA, bopC e bopD. Até o momento, não existem registros nem dados de outros estudos envolvendo a incidência dos genes do operon bopABCD em cepas de E. faecalis ou em outras espécies do gênero Enterococcus. Este estudo é o primeiro a estimar a incidência de fatores de virulência de E. faecalis isolados de frangos que receberam uma solução contendo oocistos de Eimeria maxima e Eimeria acervulina e dieta padrão contendo ou não anticoccidiano (monensina). Apesar de evidenciado o importante papel desses genes na formação e persistência do biofilme microbiano, mais pesquisas para melhor elucidar os demais fatores envolvidos na formação de biofilmes são requeridas.

0 maior índice de E. faecalis apresentando fenótipo de forte aderente, foi observado nos isolados provenientes dos frangos que receberam uma solução contendo oocistos de Eimeria maxima e Eimeria acervulina e a dieta padrão 
contendo anticoccidiano. A presença de anticoccidiano na dieta mantém a integridade intestinal, melhora a digestão e a absorção de nutrientes, disponibilizando o máximo de energia necessária para o crescimento e multiplicação celular bacteriana. Quando o animal está infectado por Eimeria spp. e o tratamento adequado não é realizado, sua integridade intestinal fica comprometida e os nutrientes normalmente usados no desenvolvimento do animal, e também dos micro-organismos presentes, não são absorvidos de maneira efetiva. Em ambos os casos, nos grupos citados anteriormente, observa-se maior índice de fortes aderentes em $36^{\circ} \mathrm{C}$ de temperatura de crescimento in vitro, sendo esta a temperatura ideal do crescimento celular de E. faecalis in vivo. Porém, altos índices também foram observados na temperatura de $42^{\circ} \mathrm{C}$, revelando adaptação dos isolados aos diferentes ambientes e temperaturas não ideais, onde ocorre aumento do seu potencial patogênico através da expressão de genes de virulência.

Em relação aos suplementos adicionados ao meio de cultura, a presença de $0,75 \%$ de glicose elevou os índices de isolados classificados como fortes aderentes em ambos os grupos de frangos e temperaturas de crescimento testadas. Entretanto, o grupo de animais que recebeu anticoccidiano na dieta, apresentou maiores índices de isolados fortes aderentes. A alta disponibilidade de nutrientes com fonte de carbono, como a glicose, permitiu maior crescimento e multiplicação das cepas e, consequente estabelecimento do biofilme microbiano. Marinho (2010) verificou que a adição 0,75\% de glicose ao meio de cultura Caldo Infusão, Cérebro e Coração também influenciou a capacidade de formação de biofilme de E. faecalis isolados de alimentos. Pillai et al. (2004) demonstraram que a formação de biofilme em placas de poliestireno foi maior em meio suplementado com $1 \%$ de glicose, concordando com nosso estudo, assim como outros estudos que mostram a influência da glicose na formação de biofilme através de um regulador transcricional dependente de glicose $(f s r)$ mediando o controle de catabólitos através da formação de proteases (Baldassarri et al. 2001, Kristich et al. 2004).

A presença de $10 \%$ de urina no meio de cultura estimulou a capacidade dos isolados em formarem biofilmes mais densos, onde $77 \%$ dos isolados que receberam anticoccidiano e $63 \%$ dos que não receberam, foram classificados como fortes aderentes. Uma explicação para este fenótipo seria primeira, que a urina além de conter ureia em grande quantidade, também apresenta fosfatos, sulfato, amônia, magnésio, cálcio, ácido úrico, creatina, sódio, potássio e outros elementos em menor quantidade. Tal composição estimula a ativação de diferentes vias metabólicas bacterianas que as torna capazes de degradar tais substâncias e captar nutrientes necessários ao crescimento e multiplicação celular e ativação de mecanismos de expressão gênica necessários para o aumento de sua patogenicidade, como a formação da estrutura do biofilme. 0 gene $a g g$, que codifica a proteína Agg, encontrado no genoma destas bactérias também exerce um papel importante in vivo, pois atua na aderência e processo inicial da infecção enterocócica em células renais e do restante do trato urinário (Seno et al. 2005). Estudos realizados com outras enterobactérias patogênicas relatam respostas de sistemas envolvidos na aquisição de ferro e genes envolvidos no metabolismo de açúcares e aminoácidos responsáveis por uma maior adaptação das cepas ao sistema urinário ou à presença de urina (Alteri \& Mobley 2007).

$O$ crescimento de E. faecalis na presença de soro sanguíneo induz a expressão de ligantes de carboidratos responsáveis pela adesão celular (Guzmán et al. 1991). O sangue contém nutrientes como as proteínas albumina e hemoglobina, ferro proveniente das células vermelhas e micronutrientes como aminoácidos, pequenos peptídeos, glicose, lipídios, ácidos graxos, fosfolipídios e triglicerídeos, além da fração celular branca. Células sanguíneas mortas podem compor a matéria orgânica necessária para a formação da matriz do biofilme e seus componentes intracelulares servirem como nutrientes para as células em biofilme, assim como células planctônicas potencialmente capazes de desencadear um novo processo de formação do biofilme microbiano. Vebo et al. (2009) analisaram isolados de E. faecalis crescidos em sangue in vitro e concluíram que a regulação dos genes e suas vias sob essas condições revelaram a capacidade de adaptação fisiológica e metabólica, principalmente no metabolismo dos carboidratos, o que pôde ser observado no grande número de isolados que demonstraram formação fenotípica menos densa, classificados como formadores moderados na presença de sangue, uma provável adaptação fisiológica ao meio ambiente em questão.

\section{CONCLUSÕES}

Comparando os resultados obtidos no presente estudo, pode-se concluir que o substrato mais favorável ao crescimento e que estimulou a aderência dos isolados de Enterococcus faecalis nas microplacas de poliestireno foi a presença de $0,75 \%$ de glicose no meio de cultura LB, independente das temperaturas de crescimento. Entretanto, os altos níveis obtidos em $42^{\circ} \mathrm{C}$ de temperatura de crescimento sugerem uma grande capacidade de adaptação dos isolados a condições e hospedeiros diversos (frangos de corte). Os resultados obtidos com suplementação de sangue e urina também apontam o grande potencial patogênico das cepas, visto seu crescimento e capacidade de formação de biofilme na presença de fluidos humanos ou animais (Wani et al. 2012).

Ressaltando a importância deste estudo, E. faecalis isolados de frangos de corte que receberam oocistos de Eimeria maxima e Eimeria acervulina e ração suplementada ou não com anticoccidiano apresentaram capacidade de se adaptar a diferentes nichos biológicos, como por exemplo, sangue e urina. Associado a esta plasticidade dos microrganismos, a capacidade dos isolados de formar biofilme e a presença de fatores de virulência sugerem que os E. faecalis isolados de frangos tratados com anticoccidiano estão mais bem adaptados ao ambiente intestinal dos animais. No futuro, estudos de expressão gênica poderão esclarecer parte desta complexa fisiologia da formação de biofilme em isolados da espécie E. faecalis.

Agradecimentos.- Ao Conselho Nacional de Desenvolvimento Científico e Tecnológico (CNPq) e a Coordenação de Aperfeiçoamento de Pessoal de Nível Superior (CAPES) pelo auxílio financeiro disponibilizado. 


\section{REFERÊNCIAS}

Alteri C.J. \& Mobley H.L. 2007. Quantitative profile of the uropathogenic Escherichia coli outer membrane proteome during growth in human urine. Infect. Immun. 75:2679-2688.

Baldassarri L., Cecchini R. \& Bertuccini L. 2001. Enterococcus spp. produces slime and survives in rat peritoneal macrophages. Med. Microbiol. Immun. 190:113-20.

Barbosa J., Gibbs P.A. \& Teixeira P. 2010. Virulence factors among enterococci isolated from traditional fermented meat products produced in the North of Portugal. Food Control. 1:651-656.

Barrow P.A. 1992. Probiotics for chickens, p.255-257. In: Fuller R. (Ed.), Probiotics: The scientific Basis. Vol.1. Chapman and Hall, London. 398p.

Bourgogne A., Hilsenbeck S.G., Dunny G.M. \& Murray B.E. 2006. Comparison of OG1RF and an isogenic $f_{s r} B$ deletion mutant by transcriptional analysis: the Fsr system of Enterococcus faecalis is more than the activator of gelatinase and serine protease. J. Bacteriol. 188:2875-2884.

Bradley R.E. \& Radhakrishnan C.V. 1973. Coccidiosis in chickens: obligate relationship between Eimeria tenella and certain species of cecalmicroflora in the pathogenesis of the disease. Avian Dis. 17:325-349.

Cassenego A.P.V., D'azevedo P.A., Ribeiro A.M.L., Frazzon J., Van Der Sand S.T. \& Frazzon A.P.G. 2011. Species distribution and antimicrobial susceptibility of enterococci isolated from broilers infected experimentally with Eimeria spp. and fed with diets containing different supplements. Braz. J. Microbiol. 42:480-488.

Chai Y., Chu F., Kolter R. \& Losick R. 2007. Bistability and biofilm formation in Bacillus subtilis. Mol. Microbiol. 67:254-263.

Creti R., Koch S., Fabretti F., Baldassarri L. \& Huebner J. 2006. Enterococcal colonization of the gastro-intestinal tract: role of biofilm and environmental oligosaccharides. BMC Microbiol. 6:60.

Depardieu F., Perichon B. \& Courvalin P. 2004. Detection of the van alphabet and identification of enterococci and staphylococci at the species level by multiplex PCR. J. Clin. Microbiol. 42:5857-5860.

Diarra M.S., Rempel H., Champagne J., Masson L., Pritchard J. \& Tropp E. 2010. Distribution of antimicrobial resistance and virulence genes in Enterococcus spp. and characterization of isolates from broiler chickens. Appl. Environ. Microbiol. 76:8033-8043.

Donelli G. \& Guaglianone E. 2004. Emerging role of Enterococcus spp. in catheter related infections: biofilm formation and novel mechanisms of antibiotic resistance. J. Vasc. Access 5:3-9.

Droleskey R.E., Oyofo B.A., Hargis B.M., Corrier D.E. \& Deloach J.R. 1994. Effect of mannose on Salmonella typhimurium-mediated loss of mucosal epithelial integrity in cultured chick intestinal segments. Avian Dis. 38:275-281.

Duprè I., Zanetti S., Schito A.M., Fadda G. \& Sechi L.A. 2003. Incidence of virulence determinants in clinical Enterococcus faecium and Enterococcus faecalis isolates collected in Sardinia (Italy). J. Med. Microbiol. 52:491-498.

Eaton T.J. \& Gasson M.J. 2001. Molecular screening of Enterococcus virulence determinants and potential for genetic exchange between food and medical isolates. Appl. Environ. Microbiol. 67:1628-1635.

Franz C.M.A.P., Muscholl-Silberhorn A.B., Yousif N.M.K., Vancanneyt M., Swings J. \& Holzapfel W.H. 2001. Incidence of virulence factors and antibiotic resistance among enterococci isolated from food. Appl. Environ. Microbiol. 67:4385-4389.

Fredricks D.N. \& Relman D.A. 1997. Cultivation of Whipple bacillus: the irony and the ecstasy. Lancet 350:1262-1263.

George S., Kishen A. \& Song K.P. 2005. The role of environmental changes on monospecies biofilm formation on root canal wall by Enterococcus faecalis. J. Endod. 31:867-72.

Guzmán C.A., Pruzzo C., Platè M., Guardati M.C. \& Calegari L. 1991. Serum dependent expression of Enterococcus faecalis adhesins involved in the colonization of heart cells. Microb. Pathog. 11:399-409.

Herrera-Luna C., Klein D., Lapan G., Revilla-Fernandez S., Haschek B., Sommerfield-Stur I., Moestl K. \& Baumgatner W. 2009. Characterization of virulence factors in Escherichia coli isolated from diarrheic and healthy calves in Austria shedding various enteropathogenic agents. Vet Med. 1:1-11.
Hufnagel M., Koch S., Creti R., Baldassarri L. \& Huebner J.A. 2004. Putative sugar-binding transcriptional regulator in a novel gene locus in Enterococcus faecalis contributes to production of biofilm and prolonged bacteremia in mice. J. Infect. Dis. 189:420-430.

Hume M.E., Hernández C.A., Barbosa N.A., Dowd S.E., Sakomura N.K. \& Oviedo-Rondón E.O. 2012. Molecular identification and characterization of ileal and cecal fungus communities in broilers given probiotics, specific essential oil blends and under mixed Eimeria infection. Foodborne Pathog. Dis. 9:853-960.

Kristich C.J., Li Y.H., Cvitkovitch D.G. \& Dunny G.M. 2004. Esp-independent biofilm formation by Enterococcus faecalis. J. Bacteriol. 186:15463.

LeBreton Y., Pichereau V., Sauvageot Y., Auffray Y. \& Rince A. 2005. Maltose utilization in Enterococcus faecalis. J. Appl. Microbiol. 98:806-813.

Macovei L., Ghosh A., Thomas V.C., Hancock L.E., Mahmood S. \& Zurek L. 2009. Enterococcus faecalis with the gelatinase phenotype regulated by the $f s r$ operon and with biofilm-forming capacity are common in the agricultural environment. Environ. Microbiol. 11:1540-1547.

Mannu L., Paba A., Daga E., Comuniana R., Zanetti S., Duprè I. \& Sechi L.A. 2003. Comparison of the incidence of virulence determinants and antibiotic resistance between Enterococcus faecium strains of dairy, animal and clinical origin. Int. J. Food Microbiol. 88:291-304.

Marinho A.R. 2010. Avaliação fenotípica e genotípica de fatores relacionados com a formação de biofilme por Enterococcus isolados de alimentos. Dissertação de Mestrado, Universidade Federal do Rio Grande do Sul, Porto Alegre, RS. 88p.

Martín M., Gutiérrez J., Criado R., Herranz C., Cintas L.M. \& Hernández P.E. 2006. Genes encoding bacteriocins and their expression and potential virulence factors of enterococci isolated from wood pigeons (Columba palumbus). J. Food Protect. 69:520-531.

Martynova-Van Klein M.A., Oviedo-Rondón E.O., Dowd S.E., Hume M. \& Nalian A. 2012. Effect of Eimeria infection on cecal microbiome of broilers fed essential oils. Int. J. Poultry Sci. 11:747-755.

Murray B.E. 1990. The life and times of the Enterococcus. Clin. Microbiol. Rev. 3:46-65.

Neish A.S. 2002. The gut microflora and intestinal epithelial cells: a continuing dialogue. Microbes Infect. 4:309-317.

Olsen H.R., Schønheyder H.C., Christensen H. \& Bisgaard M. 2011. Enterococcus faecalis of human and poultry origin share virulence genes supporting the zoonotic potential of E. faecalis. Zoon and Pub Health 59:256-263.

Piekarska K. \& Jagielski M. 2007. Prevalence of virulence associated genes of Enterococcus faecalis clinical strains isolated from patients and volunteers. Med. Dosw. Mikrobiol. 59:207-216.

Pillai S.K., Sakoulas G., Eliopoulos G.M., Moellering R.C., Murray B.E. \& Inouye R.T. 2004. Effects of glucose on $f s r$ - mediated biofilm formation in Enterococcus faecalis. J. Infect. Dis. 190:967-970.

Pires-Bouças P.D., Izumi E., Furlaneto-Maia L., Sturion L. \& Suzart S. 2010. Effects of environmental and nutritional factors on gelatinolytic activity by Enterococcus faecalis strains isolated from clinical sources. Afric. J. Microbiol. Res. 4:969-976.

Poeta P., Costa D., Rodrigues J. \& Torres C. 2006. Detection of genes encoding virulence factors and bacteriocins in fecal enterococci of poultry in Portugal. Avian Dis. 50:64-68.

Santos G.J.R., Conceição F.R. \& Gil-Turnes C. 2008. Enterite necrótica aviária. Cienc. Rural 38:2076-2082.

Seno Y., Kariyama R., Mitsuhata R., Monden K. \& Kumon H. 2005. Clinical implications of biofilm formation by Enterococcus faecalis in the urinary tract. Acta Med. 59:79-87.

Shepard B.D. \& Gilmore M.S. 2002. Differential expression of virulencerelated genes in Enterococcus faecalis in response to biological cues in serum and urine. Infect. Immun. 70:4344-4352.

Singh K.V., Coque T.M., Weinstock G.M. \& Murray B.E. 1998. In vivo testing of an Enterococcus faecalis efaA mutant and use of efaA homologs for species identification. FEMS Immunol. Med. Mic. 21:323-331. 
Smith A.L. \& Beal R. 2008. The avian enteric immune system in health and disease, p.243-271. In: Davison F., Kaspers B. \& Schat K.A. (Eds), Avian Immunology. Vol.1. Academic Press, London. 496p.

Stepanovic S., Vukovic D., Dakic I., Savic B. \& Svabic-Vlahovic M. 2000. A modifier microtiter-platetest for quantification of staphylococcal biofilm formation. J. Microbial Meth. 40:175-179.

Vebo H.C., Snipen L., Nes I.F. \& Brede D.A. 2009. The transcriptome of the nosocomial pathogen Enterococcus faecalis V583 reveals adaptive responses to growth in blood. Plos One. doi:10.1371/journal. pone. 0007660 .

Wani S.A., Hussain I., Rather M.A., Kabli Z.A., Nagamani K., Nishikawa Y.,
Qureshi S.D. \& Khan I. 2012. Putative virulence genes and biofilm production among typical enteroaggregative Escherichia coli isolates from diarrhoeic children in Kashmir and Andhra Pradesh. Indian J. Microbiol. 52:587-592.

Williams R.B. 2005. Intercurrent coccidiosis and necrotic enteritis of chickens: rational, integrated disease management by maintenance of gut integrity. Avian Pathol. 34:159-180.

Yeong H.I., Lim S.K., Ku H.O., Park C.K., Jung S.C., Park Y.H. \& Nam H.M. 2011. Ocurrence of virulence determinants in fecal Enterococcus faecalis isolated from pigs and chickens in Korea. J. Microbial Biotech. 21:1352-1355. 